\title{
Protoporphyrin IX photobleaching of subcellular distributed sites of leukemic HL60 cells based on ALA-PDT in vitro
}

\author{
Kangqiang Huang ${ }^{1,2}, \mathrm{Li}_{\mathrm{Chen}}^{3}$, Shunfeng $\mathrm{Lv}^{2}$, Jianwen Xiong ${ }^{2 *}$ \\ ${ }^{1}$ Project Construction Center, Shantou Branch, China Mobile Group Guangdong Co., Shantou, China \\ ${ }^{2}$ Laboratory of Quantum Information Technology, School of Physics and Telecommunication Engineering, South China Normal Uni- \\ versity, Guangzhou, China \\ ${ }^{3}$ Department of Physics \& Optoelectronic Engineering, Guangdong University of Technology, Guangzhou, China \\ Email: ${ }^{\text {jwxiong@scnu.edu.cn }}$
}

Received 19 November 2011; revised 22 February 2012; accepted 10 June 2012

\begin{abstract}
The leukaemia cells HL60, incubated in $10 \mathrm{mM} / \mathrm{ml}$ ALA (5-aminolevulinic) for 4 hours, were carried an experimental research with fluorescent probes in photodynamic therapy (PDT) based on ALA by using PDT reaction room (The average fluence rate of the $412 \mathrm{~nm}$ source was $5 \mathrm{~mW} / \mathrm{cm}^{2}$ ). Cells viability were determined using a Cell Counting Kit-8 (CCK-8) assay, and PpIX Photobleaching of subcellular distributed sites of HL60 cells in vitro were investigated by fluorescence spectra acquired during treatment. The results showed that the fluorescence intensity of mitochondria, lysosomes, endoplasmic reticulum had decreased by $81.5 \%, 52.3 \%$ and $21.0 \%$, respectively, compared with their initial values after a 45-minute light treatment. The rate of PpIX photobleaching in mitochondria was significantly higher than others. Additionally, the change of the activity of HL60 cells was basically characterized by the change fluorescence intensity in mitochondria, which suggest that mitochondria is one of main therapeutic targets of photodynamic therapy.
\end{abstract}

Keywords: 5-Aminolaevulinic Acid (ALA); Photodynamic Therapy (PDT); PpIX (Protoporphyrin IX); Photobleaching; Subcellular

\section{INTRODUCTION}

Photodynamic therapy (PDT) is a relatively new treatment modality, which combines the selective accumulation of a photosensitizing drug with visible light of wavelengths within the absorption spectra of the photosensitizer to achieve the inactivation of cancerous tu-

*Corresponding author. mors [1].

In the past several decades, there has been tremendous interest in 5-aminolevulinic acid (ALA) based on PDT [2-4]. With the development of the basic research of photodynamic therapy (PDT) and a wide range of potential clinical applications have be carried out, photosensitizer photobleaching and its mechanism are not only increasingly important to photodynamic therapy dosimetry, but also to further clinical applications. Photosensitizer photobleaching and the fluorescence monitoring of photoproducts have become a highly focused area of research within PDT dosimetry in recent years [5-8]. It has been demonstrated that photobleaching can be used to monitor the processes of Photodynamic Therapy: the dose of singlet oxygen can be well predicted by the dosimetric photobleaching kinetics of photosensitizer in a photosensitizing system [9-11]. Furthermore, photosensitizer photobleaching provided a reliable method to estimate the inactivation efficacy of singlet oxygen on target tissues during treatment comprehensively, it is therefore inextricably linked with the effectiveness of PDT $[12,13]$. The monitoring of photosensitizer photobleaching fluorescence measurement is expected to become a real-time "implicit" dosimetry method [14-17]. Therefore, it is of great significance to study the phenomenon of photosensitizer photobleaching for future clinical applications as well as the mechanism of PDT.

In this paper, the fluorescent probe labeling techniques were adopted to investigate the change fluorescence intensity of PpIX in the major subcellular structures quantitatively during treatment. The inactivation effects of leukemic HL60 cells in vitro based on ALAPDT and the photobleaching characteristics of subcellular distributed sites of HL60 cell in PDT were also discussed. 


\section{EXPERIMENTAL}

\subsection{Materials}

HL60 cells were supplied by the Laboratory Animal Center of Sun Yat-sen University (China). The fluorescent probe for mitochondria: rhodamine123, the red fluorescent probe for lysosomes: Lyso-Tracker Red, the fluorescent probe for endoplasmic reticulum: DIOC6, 5-aminolevulinic acid (ALA) and phosphate buffered saline (PBS) were purchased from Sigma (USA). Cell Counting Kit-8 (CCK-8) was purchased from Dojindo (Japan). RPMI medium 1640 and foetal calf serum (FCS) were obtained from Gibco BRL. All chemicals were of the highest purity commercially available. The tock solutions were prepared in serum free medium immediately before taken into the experiments.

These apparatus, incuding F-4500 Fluorescence Spectrophotometer (Hitachi, Japan), UV-2550 UV-visible Spectrophotometer (Hitachi, Japan), NIR256 Fiber Optic Spectrometers (Ocean Optics, USA), DG5031 ELISA Reader (Huadong, China), HH.CP-TW80 CO Incubator, XDS-1A Inverted Microscope, PDT light reaction chamber, 96-well culture plates, cell counting board and so on were used in the experiments.

\subsection{Methods}

HL60 human leukemia cells were grown in RPMI medium 1640 supplemented with $10 \%$ fetal bovine serum, then incubated at $37^{\circ} \mathrm{C}$ in a humidified atmosphere containing 5\% $\mathrm{CO}_{2}$. All experiments were performed using exponentially growing HL60 cells. Cell concentration was determined using a cell count board and the cell density was then adjusted to the required concentration.

The viability of HL60 cells after treatment was assessed using CCK-8 (Cell Counting Kit-8), which is based on the amount of highly water-soluble formazan dye produced by viable cells [18]. The number of surviving cells is directly proportional to the absorbance of formazan. Cell suspension $(100 \mu \mathrm{l})$ was seeded onto a 96-well plate and incubated with $20 \mu \mathrm{l} \mathrm{CCK-8} \mathrm{solution} \mathrm{at}$ $37^{\circ} \mathrm{C}$ in a humidified $5 \% \mathrm{CO}_{2}$ atmosphere. Besides, appropriate volume of cell culture medium was added to ensure that the final volume of samples was $200 \mu \mathrm{l}$. After $4 \mathrm{~h}$ incubation, the absorbance at $450 \mathrm{~nm}$ was determined using the DG5031 ELISA Reader. The relative viability was determined by comparison with untreated cells.

Data are presented as means \pm S.D. (standard deviation) from at least three independent experiments. Statistical analyses were performed using the SPSS11.5 statistical software, results were considered to be significant when the corrected P-value was less than 0.05, indicated as $\mathrm{P}<0.05$ in the figures.

\section{RESULTS AND DISCUSSION}

\subsection{Spectral Analysis}

ALA itself is not a photosensitizer, however it represents a approach in which a photosensitizer precursor naturally occurring in the heme biosynthesis pathway is administered, and the photosensitizer PpIX is subsequently synthesized in living cells. The absorption spectrum of PpIX was measured by UV-2550 UV-visible Spectrophotometer (Hitachi, Japan). As shown in Figure 1, the absorption peaks of PpIX is located at $412 \mathrm{~nm}$, which indicated that the most sensitive wavelength of PpIX to light irradiation is at around $412 \mathrm{~nm}$. Therefore, in order to enhance the efficiency of PDT, an in-house built lamp with many high-power light-emitting diodes (LEDs), emitting light in the region $400-450 \mathrm{~nm}$ and with a peak at 412 $\mathrm{nm}$ as shown in Figure 2, was taken as light sources in the experiments. The fluence rate at the position of the sample was $5 \mathrm{~mW} / \mathrm{cm}^{2}$ as measured with a photodiode.

\subsection{Inactivation of Leukemic HL60 Cells in Vitro Based on ALA-PDT}

The inactivation of HL60 base on ALA-PDT irradiated

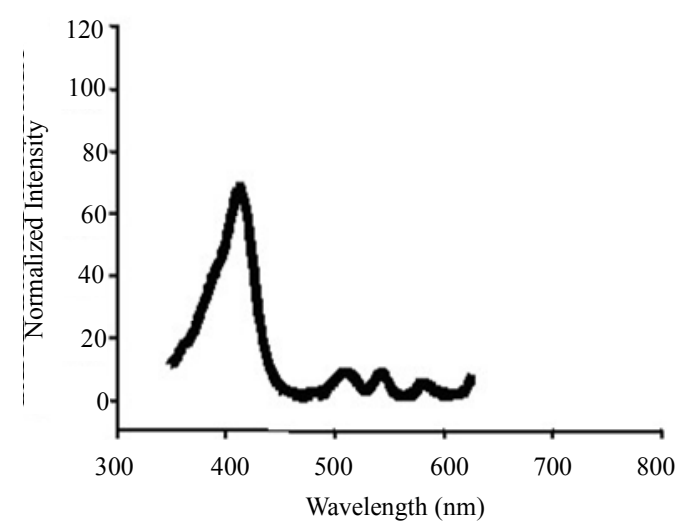

Figure 1. The absorption spectrum of PpIX.

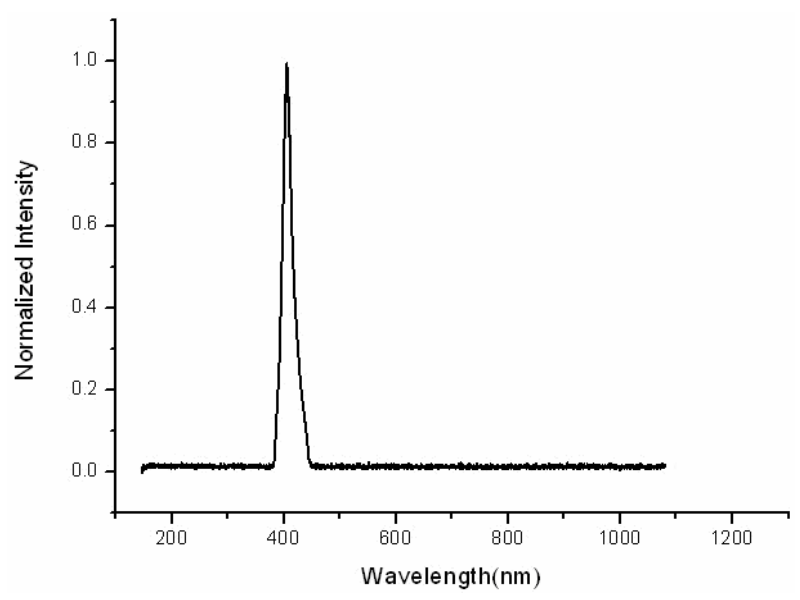

Figure 2. The emission spectra of the blue LEDs. 
by $412 \mathrm{~nm}$ light was taken to provide experimental data reference for PpIX photobleaching of subcellular distributed sites in HL60 at the macro. According to our previous investigations, it has been noted that therapeutics are extremely effective under these parameters (the density of HL60 cells is $1 \times 10^{6} / \mathrm{ml}$, the cells incubation time is 4 hours, the concentration of ALA is $10 \mathrm{mM} / \mathrm{ml}$, the average fluence rate of the $412 \mathrm{~nm}$ source is $5 \mathrm{~mW} / \mathrm{cm}^{2}$, and the dose of irradiation was $18 \mathrm{~J} / \mathrm{cm}^{2}$ ), which are consistent with the literatures reports [19-21]. Firstly, the density of $1 \times 10^{6} / \mathrm{ml}$ of HL60 cells suspension was added the concentration of $10 \mathrm{mM} / \mathrm{ml}$ ALA. Light exposure was performed immediately after incubation for $4 \mathrm{~h}$ in the dark. Finally, cell survival was assessed by CCK-8.

These experiments were repeated five times independently in the same conditions, the OD (optical density) values of the five samples were measured by using the DG5031 ELISA Reader. The OD values obtained from the cells after light treatment (expressed by $\mathrm{OD}_{\mathrm{R}}$ ) were normalized by these before light irradiation (expressed by $\mathrm{OD}_{\mathrm{w}}$ ). The relative survival rate of HL60 cells under various conditions (indicated by $\mathrm{S}$ ), namely:

$$
\mathrm{S}=\frac{\mathrm{OD}_{\mathrm{R}}}{\mathrm{OD}_{\mathrm{W}}}
$$

The experimental data are presented in Table 1.

According to Table 1, the influence of $412 \mathrm{~nm}$ light irradiation on the survival of HL60 cells also as shown in Figure 3.

The A-NI group and NA-I group were compared with NA-NI groups, respectively, It is observed that neither the alone addition of ALA or light irradiation has an obviously impact on the activity of HL60 cells. However, a significantly greater decrease in the survivability of HL60 cell can be found after light treatment for $1 \mathrm{~h}$ in the presence of ALA when AI group compared with A-NI group or the NA-I group. Apparently, the decreased survivability of HL60 cells is not due to the addition of ALA or light irradiation alone, but because of the combination of ALA and light irradiation that resulted in outcome of PDT.

The inactivation efficiency is calculated by the formula as follows:

$$
\mathrm{P}_{\mathrm{e}}=1-\mathrm{OD}_{\mathrm{R}} / \mathrm{OD}_{\mathrm{W}}
$$

According to the above formula, the PDT efficiency of HL60 was achieved at $92 \%$ under the combination of ALA and $412 \mathrm{~nm}$ light irradiation.

\subsection{PpIX Photobleaching of Subcellular Distributed Sites in HL60 during PDT}

Firstly, the fluorescent probe liquors, including Rhodamine 123 at a final concentration of $1 \mu \mathrm{M} / \mathrm{ml}$, the LysoTracker Red at a final concentration of $75 \mathrm{nM} / \mathrm{ml}$, DIOC6 at a final concentration of $2 \mu \mathrm{g} / \mathrm{ml}$, were prepared before the experiments.

HL60 cells washed with PBS were seeded into 15 wells of 96-well plates at a density of approximately $1 \times$ $10^{6}$ cells per ml, Afterwards, The solution of ALA with a known concentration $(10 \mathrm{mM} / \mathrm{ml})$ were added to the 15 wells. Light exposure was carried out immediately after incubating for 4 hours. Owe to the viability of HL60 cell is only $8 \%$ after 60 minutes light treatment, three samples were removed from 96 -well culture plates on $0 \mathrm{~min}$, $15 \mathrm{~min}, 30 \mathrm{~min}, 45 \mathrm{~min}, 60 \mathrm{~min}$, respectively. Cell culture medium was removed and the prepared fluorescent probes liquor of mitochondria, lysosomes, endoplasmic reticulum were added to the three samples respectively. After pre-incubated for 15 minutes in the dark, the working solution of the three samples was removed and added fresh cell culture medium. Subsequently, the fluorescence spectra of these samples were performed using F-4500 fluorescence spectrophotometer. The excitation light from the fluorescence spectrophotometer was of low intensity (less than $1 \mathrm{~mW} / \mathrm{cm}^{2}$ ) and did not induce any significant photobleaching of PpIX.

As can be seen from Figure 4 that the fluorescence intensity of organelles did not change significantly when

Table 1. The influence of $412 \mathrm{~nm}$ light irradiation on the survivability of HL60 cells in the experiments based on ALA-PDT exam-

\begin{tabular}{|c|c|c|c|c|c|c|c|}
\hline & \multicolumn{5}{|c|}{ OD Value } & \multirow{2}{*}{ Mean Value } & \multirow{2}{*}{ Mean Livability } \\
\hline & $\mathrm{A}$ & $\mathrm{B}$ & $\mathrm{C}$ & $\mathrm{D}$ & $\mathrm{E}$ & & \\
\hline NA-NI* & 0.764 & 0.800 & 0.774 & 0.751 & 0.856 & $0.789 \pm 0.042$ & 1 \\
\hline A-NI & 0.825 & 0.817 & 0.800 & 0.793 & 0.900 & $0.827 \pm 0.043$ & 1.04 \\
\hline NA-I & 0.772 & 0.750 & 0.721 & 0.765 & 0.800 & $0.762 \pm 0.029$ & 0.96 \\
\hline AI & 0.075 & 0.075 & 0.075 & 0.077 & 0.081 & $0.077 \pm 0.003$ & 0.08 \\
\hline $\mathrm{BB}$ & 0.063 & 0.064 & 0.061 & 0.062 & 0.085 & $0.067 \pm 0.010$ & I \\
\hline AA & 0.069 & 0.065 & 0.076 & 0.085 & 0.056 & $0.070 \pm 0.011$ & 1 \\
\hline
\end{tabular}
ined by CCK-8. $\left\{1 \times 10^{-8} \mathrm{mmol} / \mathrm{cell} \mathrm{ALA}(4 \mathrm{~h})+\left(18 \mathrm{~J} / \mathrm{cm}^{2}\right)+\mathrm{CCK}-8(4 \mathrm{~h})\right\}$.

*In Table 1, NA-NI (without ALA or light irradiation); A-NI (ALA without light irradiation); NA-I (light irradiation without ALA); AI (light irradiation with ALA); BB (the control group only added culture medium); AA (the control group with a specific concentration of ALA). Data represent the means \pm S.D. (standard deviation) from five independent experiments. ${ }^{*} \mathrm{P}<0.05$ as compared to control (untreated) cells. 


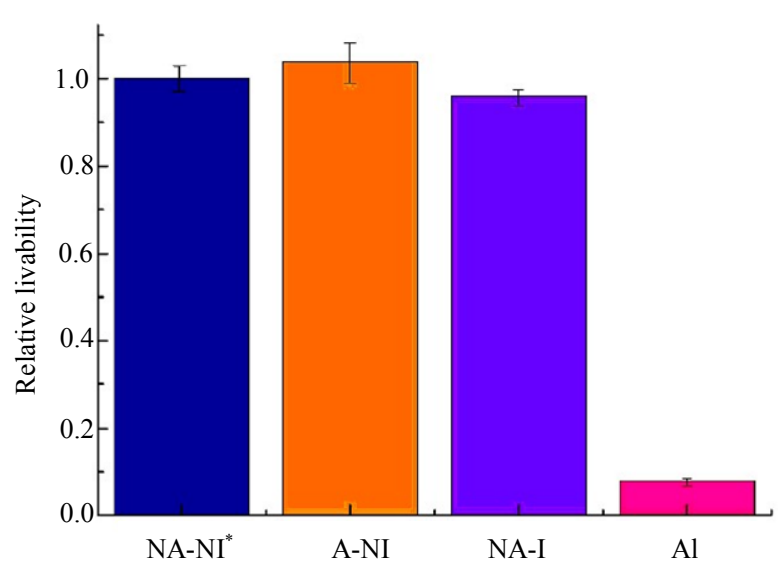

Figure 3. The influence of $412 \mathrm{~nm}$ light irradiation on the survivability of HL60 cell in the experiments based on ALA-PDT measured by CCK-8. $\left\{1 \times 10^{-8} \mathrm{mmol} / \mathrm{cell} \operatorname{ALA}(4 \mathrm{~h})+\left(18 \mathrm{~J} / \mathrm{cm}^{2}\right)\right.$ + CCK-8 (4 h) $\}$. Data represent the means \pm S.D (standard deviation) from five independent experiments. ${ }^{*} \mathrm{P}<0.05$ as compared to control (untreated) cells.

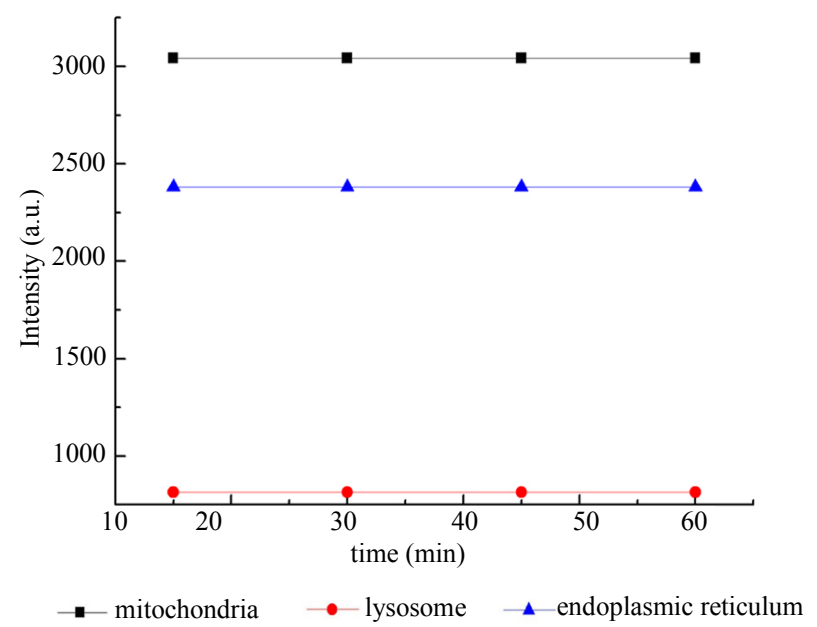

Figure 4. The influence of light irradiation on the fluorescence intensity of subcellulars of HL60 cells without ALA.

exposed to light without ALA, and the values of fluorescence intensity of subcellulars remain flat. Meanwhile, the emission wavelength and the excitation wavelength of the three fluorescent probes did not overlap with each other, so the reliability of measurement was guaranteed.

The variation of the fluorescence intensity in mitochondria under $412 \mathrm{~nm}$ light irradiation was determined by F-4500 Fluorescence Spectrophoto-meter as shown below (Fluorescence of mitochondria was excited at 480 $\mathrm{nm})$.

The variation of the fluorescence intensity in Lysosomes under $412 \mathrm{~nm}$ light irradiation as shown below (Fluorescence of lysosomes was excited at $577 \mathrm{~nm}$ ).

The variation of fluorescence intensity in endoplasmic reticulum under $412 \mathrm{~nm}$ light irradiation as shown below (Fluorescence of endoplasmic reticulum was excited at
$500 \mathrm{~nm})$.

All the amplitudes of the above fluorescence spectra obtained from subcellulars are normalized to the initial (pre-irradiation) amplitude prior to averaging. According to Figure 5(b), the fluorescence intensity of mitochondria has decreased exponentially during light exposure. From 15 minutes to 45 minutes, the rate of decrease in fluorescence intensity of mitochondria is the fastest, suggesting that the majority of the inactivation of photosensitizer to mitochondria is occurring focus on this time. After 60 minutes, the fluorescence intensity of mitochondria has decreased by $95 \%$ compared with its initial value. As shown in Figure 6(b), the fluorescence intensity of lysosomes decreases slowly at the first 15 minutes, After 15 minutes, the average decline rate is approximately $13 \%$ every 15 minutes which is similar to the linear decline. To reach 60 minutes, the fluorescence in-

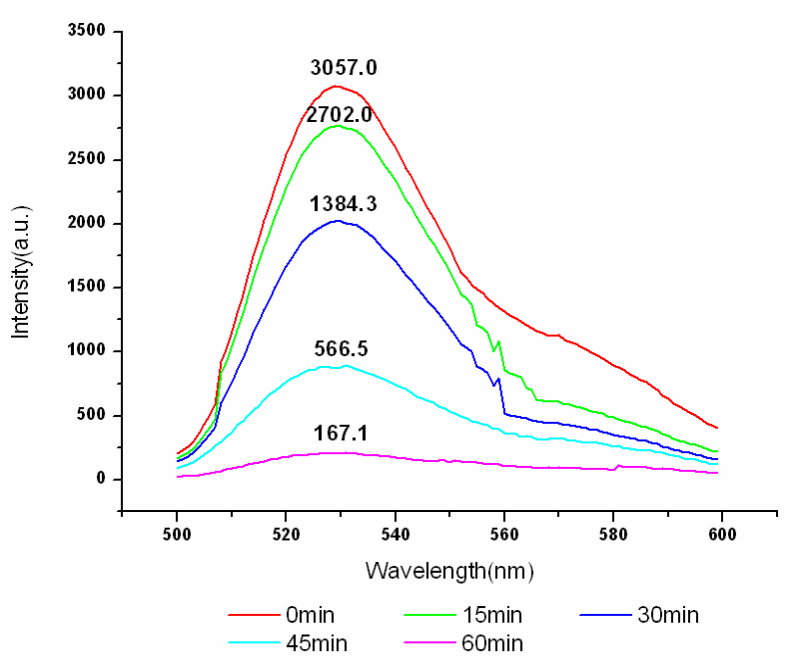

(a)

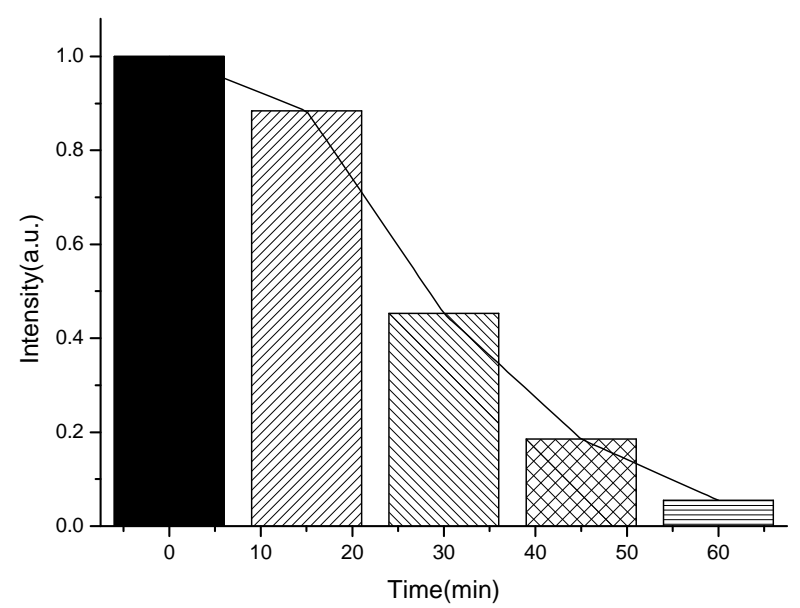

(b)

Figure 5. (a) Changes in the fluorescence of mitochondria in the presence of ALA under $412 \mathrm{~nm}$ light irradiation; (b) The normalized fluorescence intensity of mitochondria with ALA under $412 \mathrm{~nm}$ light irradiation. 


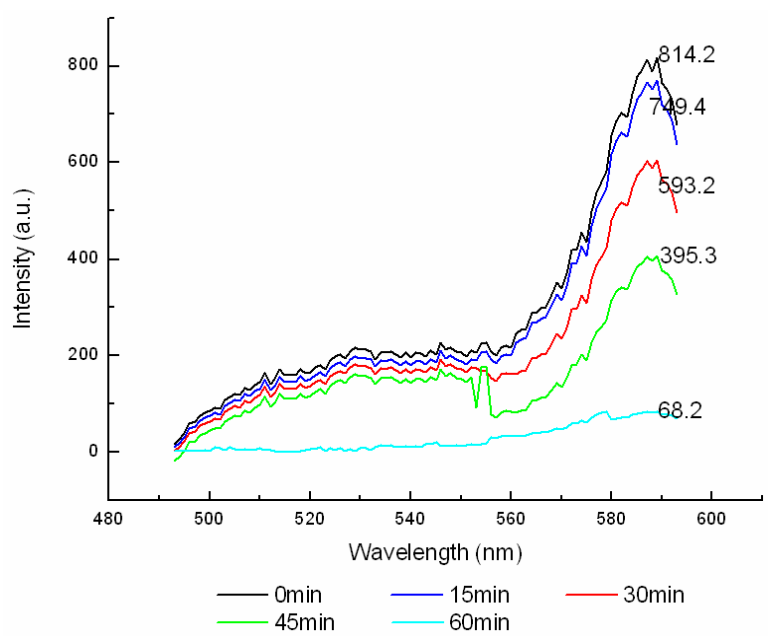

(a)

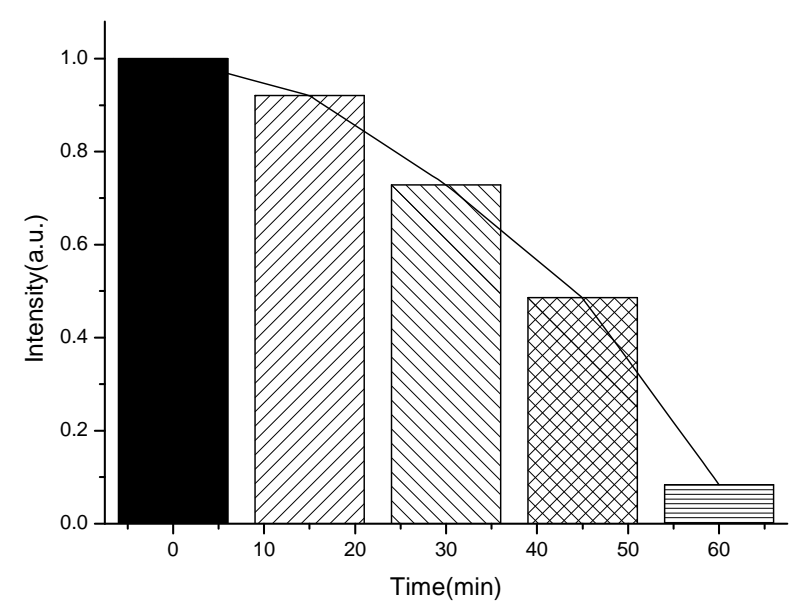

(b)

Figure 6. (a) Changes in the fluorescence of lysosomes in the presence of ALA under $412 \mathrm{~nm}$ light irradiation; (b) The normalized fluorescence intensity of lysosomes with ALA under $412 \mathrm{~nm}$ light irradiation.

tensity of lysosomes plunges rapidly to less than $1 \%$ of its initial value. As shown in Figure 7(b), the change of the fluorescence intensity in endoplasmic reticulum is even more slowly compared with that in mitochondria and lysosomes. It is found that the fluorescence intensity in endoplasmic reticulum only decrease by $21 \%$ after 45 minutes light treatment. However, the fluorescence intensity begins to decline sharply after 45 minutes, the situation is similar to the changes of the fluorescence intensity in lysosomes during the last 15 minutes. This phenomenon can be explained by the fact that the activity of the intracellular organelles have decreased to apoptosis caused by the necrosis of most of HL60 cell in a short time when irradiated reaches 60 minutes, resulting in the fluorescence intensity in the endoplasmic reticulum and lysosomes are decreased significantly. Furthermore, after irradiation with $412 \mathrm{~nm}$ for 60 minutes, the fluorescence intensity of mitochondrial have de-

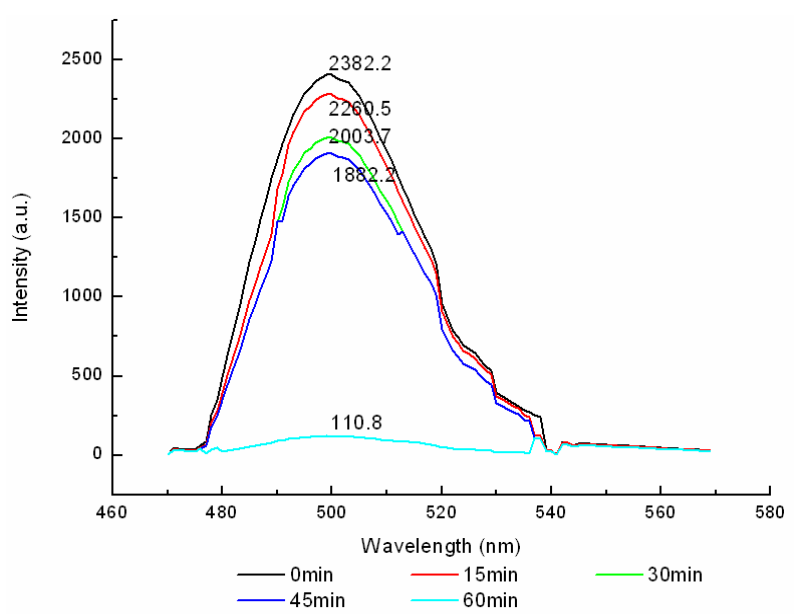

(a)

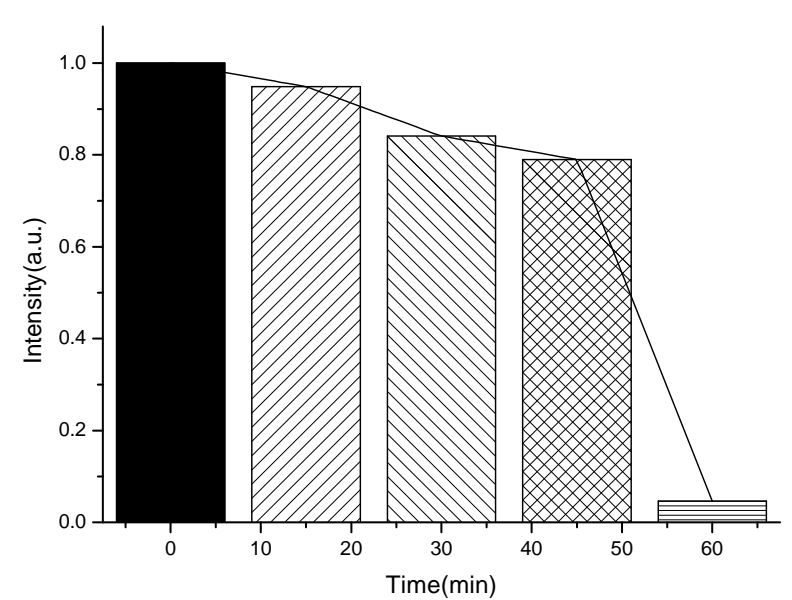

(b)

Figure 7. (a) Changes in the fluorescence of endoplasmic reticulum in the presence of ALA under $412 \mathrm{~nm}$ light irradiation; (b) The normalized fluorescence intensity of endoplasmic reticulum with ALA under $412 \mathrm{~nm}$ light irradiation.

creased by $95 \%$, which is relatively closely to the inactivation rate of HL60 cells is achieved at 92\%. It is suggested that the viability of HL60 cells are basically characterized by the change of the fluorescence intensity in mitochondria, this conclusion is in agreement with the studies done by J. C. Kennedy et al., who have found that mitochondria phototoxicity is a primary cause of cell death [4].

During light exposure, the generated endogenous PpIX will transition from the ground state to the excited state and produce photosensitizing effects with the singlet oxygen. The highly toxic singlet oxygen has a short lifetime (50 ns to $250 \mathrm{~ns}$ ) in biological systems [22], besides fluorescence intensity is directly proportional to concentration, indicating the decreased fluorescence intensity of organelle reflects the fact the photosensitizer concentration of organelle in the cells have decreased [23,24]. Another aspect is also reflected that the level of photosensitive and self-sensitized photosensitive reaction in the 
organelles of HL60. Moreover, the number of reactive oxygen in photosensitive reaction can be confirmed in turn. Since both photobleaching and cell photoinactivation are dependent on singlet oxygen generation, the rate of PpIX photobleaching can be used to estimate the singlet oxygen yield and the expected therapeutic efficiency.

\subsection{Possible Mechanism of PpIX Photobleaching Based on ALA-PDT}

It has been demonstrated that the photodynamic effects based on ALA is mainly mediated by type II reactions generating singlet oxygen [25]. Regardless of complexity, it is apparent that there are several key photochemical reactions have been involved during photodynamic therapy which could be explained as follows:

$$
\begin{aligned}
& \mathrm{I}+\mathrm{S}_{0} \stackrel{\mathrm{k}_{1}}{\longrightarrow} \mathrm{S}^{*} \\
& \mathrm{~S}^{*} \stackrel{\mathrm{k}_{2}}{\longrightarrow} \mathrm{S}_{\mathrm{T}} \\
& \mathrm{S}_{\mathrm{T}}+{ }^{3} \mathrm{O}_{2} \stackrel{\mathrm{k}_{3}}{\longrightarrow}{ }^{1} \mathrm{O}_{2}+\mathrm{S}_{0} \\
& \mathrm{~S}_{0}+{ }^{1} \mathrm{O}_{2} \stackrel{\mathrm{k}_{4}}{\longrightarrow} \mathrm{S}^{\prime}+\mathrm{O}_{2} \\
& { }^{1} \mathrm{O}_{2}+\mathrm{Bio} \stackrel{\mathrm{k}_{5}}{\longrightarrow} \text { photoproducts }+\mathrm{O}_{2}
\end{aligned}
$$

The photophysical processes are initiated by the absorption of a photon from the ground state photosensitizer molecule $\left(\mathrm{S}_{0}\right)$, creating to an excited state molecule $\left(\mathrm{S}^{*}\right)$. Afterwards, the singlet state photosensitizer $\left(\mathrm{S}^{*}\right)$ with an extremely short lifetime will transform into a relatively long lifetime triplet state $\left(\mathrm{S}_{\mathrm{T}}\right)$ immediately through intersystem crossing. The excited photosensitizer then reacts with the ground state oxygen $\left({ }^{3} \mathrm{O}_{2}\right)$ to produce singlet oxygen $\left({ }^{1} \mathrm{O}_{2}\right)$. On the one hand, the generated singlet oxygen reacts with the photosensitizer in ground state to produce substances without photosensitizing activity, the phenomenon as described above is known as photobleaching. On the other hand, it reacts with the biological macromolecules to damage the target tissue, or to generate free radicals and other highly active substances. As can be seen from the above reactions, photosensitizer photobleaching is a chain reactions accompanied through photosensitization processes. Due to the processes of ALA induced Protoporphyrin IX photobleaching exhibited a complex series of photophysical and photochemical reactions and the bleaching kinetics are much more complicated [26,27]. Therefore, further investigations are required to evaluate the Protoporphyrin IX Photobleaching based on ALA-PDT by the means of combining experiments and theoretical analysis.

\section{CONCLUSION}

In this work, we have investigated the PpIX photobleaching of subcellular distributed sites in leukemic
HL60 cells during PDT under $412 \mathrm{~nm}$ light irradiation in vitro and demonstrated that monitoring photosensitiser photobleaching is appropriate candidate for estimating PDT dose during treatment. The results showed that photodynamic effects may lead to different amounts of singlet oxygen produced in the subcellular structures, by which the varying degrees of photobleaching is caused. Irradiated by $412 \mathrm{~nm}$ light for 45 minutes, the fluorescence intensity of mitochondria, lysosomes, endoplasmic reticulum have decreased corresponding to: $81.5 \%, 52.3 \%$, $21.0 \%$, respectively. For HL60 cells, the photobleaching levels of subcellular structures are: mitochondria $>$ lysosomes $>$ endoplasmic reticulum. The rate of PpIX photobleaching in mitochondrial region is found to be significantly faster than others. The activity of the HL60 cells is also largely characterized by the change of the fluorescence intensity in mitochondria. These results indicate that mitochondria are the major sites of photodynamic reaction.

\section{ACKNOWLEDGEMENTS}

This work has been financially supported by National Natural Science Foundation of China (61072029), Natural Science Foundation of Guangdong Province (10151063101000025), and Science and Technology Planning Project of Guangzhou city (2010Y1-C111).

\section{REFERENCES}

[1] Nyman, E.S. and Hynninen, P.H. (2004) Research advances in the use of tetrapyrrolic photosensitizers for photodynamic therapy. Journal Photochem Photobiol B: Biology, 73, 1-28. doi:10.1016/j.jphotobiol.2003.10.002

[2] Lesar, A., Ferguson, J. and Moseley, H. (2011) An investigation of the fluorescence induced by topical application of 5-aminolaevulinic acid and methyl aminolaevulinate at different body sites on normal human skin. Photodiagnosis and Photodynamic Therapy, 8, 20-28.

[3] Grebenova, D., Cajthamlova, H., Bartosova, J., Marinov, J., Klamova, H., Fuchs, O. and Hrkal, Z. (1998) Selective destruction of leukaemic cells by photo-activation of 5aminolaevulinic acid induced protoporphyrinIX. Journal Photochem Photobiol B, 47, 74-81.

doi:10.1016/S1011-1344(98)00206-1

[4] Kennedy, J.C., Pottier, R.H. and Pross, D.C. (1990) Hotodynamic therapy with endogenous protoporphyrin IX: Basic with principles and presentclinical experience. Journal Photochem Photobiol B, 6, 143-148. doi:10.1016/1011-1344(90)85083-9

[5] Tyrrell, J., Campbell, S.M. and Curnow, A. (2010) Protoporphyrin IX photobleaching during the light irradiation phase of standard dermatological methyl-aminolevulinate photodynamic therapy. Photodiagnosis and Photodynamic Therapy, 7, 232-238. doi:10.1016/j.pdpdt.2010.09.005

[6] Tyrrell, J., Campbell, S.M. and Curnow, A. (2011) The effect of air cooling pain relief on protoporphyrin IX pho- 
tobleaching and clinical efficacy during dermatological photodynamic therapy. Journal of Photochemistry and Photobiology B: Biology, 103, 1-7. doi:10.1016/i.jphotobiol.2010.12.011

[7] Dysart, J.S., Singh, G. and Patterson, M.S. (2005) Calculation of singlet oxygen dose from photosensitizer fluorescence and photobleaching during mTHPC photodynamic therapy of MLL cells. Photochemistry and Photobiology, 81, 196-205. doi:10.1562/2004-07-23-RA-244.1

[8] Sudworth, C.D., Stringer, M.R., Cruse-Sawyer, J.E. and Brown, S.B. (2003) Fluorescence microspectroscopy technique for the study of intracellular protoporphyrin IX dynamics. Applied Spectroscopy, 57, 682-688. doi:10.1366/000370203322005382

[9] Dysart, J.S. and Patterson, M.S. (2005) Characterization of photofrin photobleaching for singlet oxygen dose estimation during photodynamic therapy of MLL cells in vitro. Physics in Medicine and Biology, 50, 2597-2616. doi:10.1088/0031-9155/50/11/011

[10] Mikolajewska, P., Juzenienea, A. and Moan, J. (2007) The effect of lidocaine on PpIX photobleaching and outcome of ALA-PDT in vitro. Photodiagnosis and Photodynamic Therapy, 4, 249-253. doi:10.1016/j.pdpdt.2007.10.002

[11] Moan, J., Streckyte, G., Bagdonas, S., Bech, O. and Berg, K. (1997) Photobleaching of protoporphyrin IX in cells incubated with 5-aminolevulinic acid. International Journal of Cancer, 70, 90-97. doi:10.1002/(SICI)1097-0215(19970106)70:1<90::AID-I JC14>3.0.CO;2-H

[12] Dysart, J.S. and Patterson, M.S. (2002) Relationship between mTHPC fluorescence photobleaching and cell viability during in vitro photodynamic treatment of DP16 cells. Photochemistry and Photobiology, 75, 289-295. doi:10.1562/0031-8655(2002)075<0289:RBMFPA $>2.0$.C $\underline{\mathrm{O} ; 2}$

[13] Strauss, W.S., Sailer, R., Gschwend, M.H., Emmert, H., Steiner, R. and Schneckenburgere, H. (1998) Selective examination of plasma membrane associated photosensitizers using total internal reflection fluorescence spectroscopy: Correlation between photobleaching and photodynamic efficacy of protoporphyrin IX. Photochemistry and Photobiology, 67, 363-369. doi:10.1111/j.1751-1097.1998.tb05211.x

[14] Sullivan, K.D., Sipprell, W.H. and Brown, E.B. (2009) Improved model of fluorescence recovery expands the application of multiphoton fluorescence recovery after photobleaching in vivo. Biophysical Journal, 96, 5082-5094. doi:10.1016/j.bpj.2009.04.020

[15] Boere, I.A., Obinson, D.J., Tilanus, H.W., Bruin, R.W.F., et a1., (2003) Monitoring in situ dosimetry and protoporphyrin IX fluorescence photobleaching in the normal rat esophagus during 5-aminolevulinic acid photodynamic therapy. Photochemistry and Photobiology, 78, 271-277. doi:10.1562/0031-8655(2003)078<0271:MISDAP $>2.0 . C O ; 2$

[16] Zeng, H., Korbelik, M., McLean, D.I., MacAulay, C. and Lui, H. (2002) Monitoring photoproduct formation and photobleaching by fluorescence spectroscopy has the potential to improve PDT dosimetry with a verteporfin-like photosensitizer. Photochemistry and Photobiology, 75, 398-
405 .

doi:10.1562/0031-8655(2002)075<0398:MPFAPB >2.0.CO;2

[17] Tyrrell, J., Campbell, S.M. and Curnow, A. (2010) The relationship between protoporphyrin IX photobleaching during real-time dermatological methyl-aminolevulinate photodynamic therapy (MAL-PDT) and subsequent clinical outcome. Lasers in Surgery and Medicine, 42, 613619. doi:10.1002/1sm.20943

[18] Xiong, J.W., Xiao, H., Chen, L., Wu, J.M. and Zhang, Z.X. (2007) Research on different detection conditions between MTT and CCK-8. Acta Laser Biology Sinica, 16, 526-531.

[19] Zhang, Z.X., Zhang, S.J., Zhang, B.Q. and Chen, M.L. (2005) leukemic cells killed by photodynamic therapy with 5-Aminolevulinic acid: An experimental study. Chinese Journal of Laser Medicine \& Surgery, 14, 249-252.

[20] Xiao, H., Xiong, J.W., Wu, J.M. and Zhang, Z.X. (2004) Research of parameters on ALA-PDT destruction of leukaemie cell. Acta Laser Biology Sinica, 13, 353-357.

[21] Chang, C.P., Nagel, D.J. and Zaghloul, M.E. (2011) Irradiance dependence of photobleaching of resorufin. Journal of Photochemistry and Photobiology A: Chemistry, 217, 430-432. doi:10.1016/j.jphotochem.2010.11.008

[22] Moan, J. and Berg, K. (1991) The photodegradation of porphyrins in cells can be used to estimate the lifetime of singlet oxygen. Photochemistry and Photobiology, 53, 549-553. doi:10.1111/j.1751-1097.1991.tb03669.x

[23] Koniga, K., Desserichb, M.T.W., Tadirc, Y., Hallerb, U., Trombergc, B., Bernsc, M.W. and Wyssb, P. (2006) Modifications of protoporphyrin IX fluorescence during ALAbased photodynamic therapy of endometriosis. Medical Laser Application, 21, 291-297. doi:10.1016/j.mla.2006.07.003

[24] Tyrrell, J., Campbell, S.M. and Curnow, A. (2011) Monitoring the accumulation and dissipation of the photosensitizer protoporphyrin IX during standard dermatological methyl-aminolevulinate photodynamic therapy utilizing noninvasive fluorescence imaging and quantification. Photodiagnosis and Photodynamic Therapy, 8, 30-38. doi:10.1016/j.pdpdt.2010.11.001

[25] Tyrrell, J., Campbell, S.M. and Curnow, A. (2009) The validation of a non-invasive fluorescence imaging system to monitor clinical dermatological photodynamic therapy. Photodiagnosis and Photodynamic Therapy, 7, 86-97. doi:10.1016/j.pdpdt.2010.03.002

[26] Bagdonas, S., Ma, L.W., Iani, V., Rotomskis, R., Juzenas, P. and Moan, J. (2000) Phototransformations of 5-aminolevulinic acid-induced protoporphyrin IX in vitro: A spectroscopic study. Photochemistry and Photobiology, 72, 186-192. doi:10.1562/0031-8655(2000)072<0186:POAAIP >2.0.CO;2

[27] Ascencio, M. Collinet, P., Farine, M.O. and Mordon, S. (2008) ProtoporphyrinIX fluorescence photobleaching is a useful tool to predict the response of rat ovarian cancer following hexaminolevulinate photodynamic therapy. $L a-$ sers in Surgery and Medicine, 40, 332-341. doi:10.1002/lsm.20629 


\section{Abbreviations}

NGF: Nerve growth factor;

UCMS: Unpredictable chronic mild stress;

VAP: Average path velocity;

VSL: Straight line velocity;

VCL: Curvilinear velocity;
ALH: Amplitude of lateral head displacement; BCF: Beat-cross frequency;

STR: Straightness;

LIN: Linearity;

CASA: Computer assisted sperm analysis. 